\title{
EL REVISIONISMO GARANTISTA EN EL PROCESO CIVIL A TRAVÉS DE LAS IDEAS DE FRANZ KLEIN Y ADOLF WACH. PRECISIONES SOBRE EFICIENCIA Y DERECHOS PROCESALES
}

[Revisionism of the Legal Proceedings in the Civil Procedure Through Franz Klein and Adolf Wach'S ideas. Clarifications on Efficiency and Procedural Rights]

\author{
Álvaro Pérez Ragone* \\ Pontificia Universidad Católica de Valparaíso, Chile
}

\begin{abstract}
RESUMEN
Las propuestas tanto de Franz Klein como las observaciones que hiciera Adolf Wach estaban destinadas a transparentar y objetivar una adecuada gestión del proceso sin anular ni excluir responsabilidades y roles. Las partes siguen asumiendo y detentando los poderes de siempre en relación con el objeto litigioso e, incluso, en algunos aspectos con el proceso mismo. El rol activo del tribunal queda magnificado y adecuado en lugar de ser limitado. Más bien puede decirse que se explicitan las responsabilidades de cada uno frente y dentro de un proceso sincerando las finalidades de éste y los recursos con los que se cuenta para la consecución de ello en cada caso concreto.
\end{abstract}

\footnotetext{
Palabras Clave

Franz Klein - Adolf Wach - Garantías procesales - Poderes del juez.
}

Abstract

Both Franz Klein's proposals and Adolf Wach's comments were aimed at making the correct management of the legal process more transparent and at objectifying it without cancelling or excluding responsibilities and roles. The parties continue to assume and hold the usual powers related to the matter of the litigation and even some aspects of the process itself. The active role of the court, instead of being limited, becomes magnified and adequate. It rather explains the responsibilities of each party regarding a legal process, by explaining in further detail the aims of said procedure and the resources available to do so in each case in particular.

\section{KEYWORDS}

Franz Klein - Adolf Wach - Legal proceedings - Powers of the judge.

RECiBIDo el 25 de marzo y ACEPTADo el 7 de junio de 2014

* Profesor de derecho procesal civil de la Pontificia Universidad Católica de Valparaíso. Dirección postal: Facultad de Derecho, Pontificia Universidad Católica de Valparaíso, Casilla 4059, Valparaíso, Chile. Correo electrónico: alvaro.perez@ucv.cl 


\section{INTRODUCCIÓN}

El aporte realizado por las visiones de Franz Klein (social) y Adolf Wach (liberal) al desarrollo del proceso civil europeo y contemporáneo parece no haber quedado reservado solo para fines del siglo XIX y comienzos del siglo $\mathrm{XX}$. Estos autores tuvieron una serie de coincidencias y diferencias en la misión y visión que reconocieron al proceso y la justicia civil. Ambos logran identificar los tres patrones o variables que se relacionan con una buena administración de justicia, lo que ya había sido mencionado por J. Bentham ${ }^{1}$. Por un lado la necesidad de un resultado o producto jurisdiccional que emane de un proceso que sea correcto, justo en definitiva legitimado. Por otro lado la consideración a toda actividad humana, más aún ésta que es por esencia compleja en los sujetos que intervienen y uno que decide en base al intercambio de información relevante estratégicamente develada. El producto final que constituye la decisión judicial requiere de tiempo, el que si se considera hipotéticamente ocupado apenas con un solo proceso, siempre existe la presión de un pronunciamiento oportuno y sin demora. Finalmente a estos dos factores ya de por sí tensionados se le suma un tercero que es el costo, o gastos de recursos. Éstos son normalmente escasos no sólo conformados por el tribunal, sus auxiliares y los costos en la recopilación y producción de la prueba relevante para un proceso. También en mayor proporción están integrados por los de asistencia y patrocinio por abogados y eventualmente otros expertos. Y no menor el costo-tiempo que significa el esperar la obtención de una decisión y su relevancia en efectos con la relación sustantiva.

El resultado de todo proceso como justo, equitativo y basado en la verdad es un derecho que reconocen todos los ordenamientos jurídicos. De esta forma, en la búsqueda de la justicia, la verdad siempre ha desempeñado y continuará desempeñando un importante papel. En la mayoría de los sistemas procesales se han elaborado reglas relacionada con la prueba, en algunos casos contenidas incluso en norma sustantivas que persiguen de alguna forma brindar una garantía de cierta acuciosidad en la recopilación, identificación y acreditación de aquella información fáctica necesaria para la aplicación del derecho. Los diferentes sistemas jurídicos asumen pues diversos caminos a partir de sus visiones y filosofía procesales y sustantivas. No sólo existen diferencias entre los sistemas del "Common Law" y "Civil Law", sino que también a niveles local, regional y nacional. La verdad como valor procesal puede tener distintos alcances, lo que determina el mosaico del sistema de

\footnotetext{
${ }^{1}$ Bentham, Jeremy, Rationale of Judicial Evidence Specially Applied to English Practice (London,1827), I, p. 34.
} 
litigación civil ${ }^{2}$. Quizás una diferencia radical tomada normalmente como punto de distinción entre dos modelos es el rol y responsabilidad atribuido a las partes y al tribunal. $\mathrm{O}$ bien existe un poder concentrado en el juez de carácter inquisitivo y con una gran autoridad; o por el contrario habría otro sistema en el cual son las partes los sujetos activos en la iniciativa y actividad procesal de todo tipo. La gran influencia demostrada en los siglos XX y XXI en los sistemas continentales europeos se fundamentan en el código procesal civil austríaco de 1895, en el cual se combina el principio de aporte probatorio e iniciativa de parte con el poder de dirección procesal en cabeza del juez. Se parte de que el rol ilimitado de la libertad de las partes pueda afectar la fijación de los hechos, la determinación de la verdad, y con ello la inversión de costo y tiempo verdaderamente necesaria para un proceso. El juez efectivamente no debiera asumir un rol de pasivo frente a las conductas estratégicas y dirección exclusiva y excluyente de las partes. Él no es un convidado de piedra, sino quien en algún momento deberá decidir. Caso contrario sería un caso según Klein de un proceso sin Cruz Roja ${ }^{3}$. Por el contrario el juez debiera asumir un rol, el que debe determinar tanto en relación al proceso como para con los que en él intervienen ${ }^{4}$.

Es cierto que la exacerbación de la verdad en tanto verdad material o legal, fue tomada curiosamente por los países de Europa del este y los antiguos integrantes de la Unión Soviética, pero en forma muy ajena de lo que era la concepción en las reformas de los sistemas continentales europeos 5 . Por un lado efectivamente el juez no era un factor determinante de dirección procesal, solamente asumía un papel asistencialista y proactivo para con la parte que carecía de asistencia letrada. Los procesos por regla no tenían un criterio de eficiencia que permitiera velar por la proporcionalidad entre tiempo, seguridad, calidad de las sentencias y costos. Las partes tenían el impulso y el tribunal solo se limitaba a garantizar la asistencia para una verdad siempre que fuera la adecuada a los valores y vigencia del régimen. En ese sentido y no

${ }^{2}$ Van Rhee, C.H. - Uzelac, Alan, The Pursuit of Truth in Contemporary Civil Procedure: Revival of Accuracy or New Balance in Favor of Effectiveness?, en VAN RHEE, C. H.- Uzelac, A. (coordinadores), Truth and Efficiency in Civil Litigation (Cambridge, Intersentia, 2012), pp. 3-9.

${ }^{3}$ KLeIn, Franz, "Pro Futuro". Betrachtungen über Probleme der Civilprozeßreform in Österreich (Wien, 1891), p. 39. El detalle del contexto de la explicación pp. 38-40.

${ }^{4}$ Ver al respecto en el modelo del proceso civil inglés la Rule 1.1 de las Civil Procedure Rules, explicada en detalle y descrito el rol cooperativo entre las partes y el tribunal puede verse Andrews, Neil, On Civil Procedure, Court proceedings (Cambridge, 2013), pp. 12-13; 705-711.

${ }_{5}^{5}$ Abolonin, Vadim - Abolonin, Gleb, Truth and Efficiency in Russian Civil Procedure, en Van Rhee, C. H. - Uzelac, A. (coordinadores), cit. (n. 2), pp. 313 ss.; igualmente en la misma obra los informes de Eslovenia y Rumania. 
en otro se interpretaba la verdad material en los antiguos sistemas comunistas. Consecuentemente bien en uno u otro extremo al que se hace mención en este trabajo. ${ }^{6}$ Ello porque la verdad, y eventualmente vinculado a ella, la calidad de la decisión no es independiente de factores como la eficiencia y los recursos empleados en forma adecuada en un tiempo determinado. La verdad aislada sin eficiencia ha sido criticada postulándose y queriéndose buscar siempre un equilibrio balanceado entre el tiempo dedicado y los recursos asignados para la obtención de un correcto resultado. Siempre teniendo en cuenta en un caso y proceso en concreto con el impacto dentro del sistema con las limitaciones en recursos personales e infraestructura. Ello es considerar también la existencia de otros casos ya existentes en el sistema y de aquellos que potencialmente debieran ingresar ${ }^{7}$.

El mismo Tribunal Europeo de Derechos Humanos fijó su atención en establecer y fijar límites temporales para satisfacer el derecho a ser juzgado dentro de un plazo razonable. Hoy por hoy se supera la visión única de decisión a cualquier costo y duración del proceso. Se parte de que, siendo los recursos escasos y necesitando el justiciable de decisiones legítimas en un tiempo oportuno, el cruce de los tres factores es relevante ${ }^{8}$. Lo correcto es la tridimensionalidad, propender a una correcta, justa y legítima sentencia, la que se asienta entre otros en el valor de la verdad?.

Este trabajo se compone de cinco secciones. En la primera se examina la figura histórica de Franz Klein y el entorno en el cual se generó el ZPO. austriaco, en una segunda sección se hace lo suyo con Adolf Wach y sus aportes. En la tercera parte se ve la historia paralela y las influencias alemana y austríaca en el nuevo proceso civil francés. Luego se realiza un análisis crítico de los resultados del aporte histórico y el contraste con el revisionismo garantista. Finalmente se exponen las conclusiones.

${ }^{6}$ Becker-Eberhard, Ekkehard, Grundlagen und Grenzen des Verhandlungsgrundsatzes, en YILDIRIM, Kamil (coordinador), Zivilprozessrecht im Lichte der Maximen (Estambul, 2001), 15, pp. 32 ss.

${ }^{7}$ Véase la nota 4; cfr. JeUland, Emmanuel, Case Management in France, en VAN RheE, C. H. - Fu, Yulin (coordinadores) Civil Litigation in China and Europe, Essays on the Role of the Judge and the Parties (New York, London, 2014), p. 349 ss.

${ }^{8}$ Verkerk, Remme, What is Judicial Case Management? en VAN RHeE, Remco (coordinador), Judicial Case Management and Efficiency in Civil Litigation (Antwerpen - Oxford, 2008), pp. 27 ss.

${ }^{9}$ GotTw Ald, Peter, Die osterreichische Zivilprozessordnung aus deutscher Sicht, en Mayr, P. G. (coordinador), 100 Österreichische Zivilprozessgesetze (Wien, 1998), pp. 180 ss. 


\section{El PROCESO CIVIL AUSTRÍACO DEL SIGLO XIX}

Franz Klein nació en el año 1854 en la ciudad de Viena. Allí también estudió y se formó. Concluyó sus estudios en derecho calificando como juez y abogado para después continuar con su formación post doctoral y recibir la venia legendi con un importante trabajo sobre la conducta procesal maliciosa de las partes ${ }^{10}$. Así obtuvo su calidad de libre docente para derecho procesal civil en 1885 seguido de la autorización para la enseñanza del derecho romano en 1891 siendo designado como docente privado primero y después como profesor extraordinario No le fue posible en su trayectoria acceder a la calidad de catedrático ordinario en su tiempo ${ }^{11}$. Su experiencia como abogado le permitió percibir en la práctica los abusos y conductas maliciosas, como así también los incentivos generados dentro de la "Ordenanza General de los Tribunales” vigente ${ }^{12}$. Desde el año 1891 asumió distintos cargos en el Ministerio de Justicia, en el cual fue designado como ministro en el año 1906 posición que detentará hasta 1908 y nuevamente en el año $1916^{13}$. En 1919 se convirtió en secretario de relaciones exteriores, e integró la delegación austríaca para la negociación de la paz en 1919. Falleció en el año $1926^{14}$.

\section{Gestación del "Código Procesal Civil" austriaco de 1895.}

Debe mencionarse que la obra magna de este jurista fue sin duda el “Código Procesal Civil” austríaco. Desde el año 1781 regía el llamado "Código Josefino" o "Código General de los Tribunales" ("Josephinische Gerichtsordnung" o Allgemeine Gerichtsordnung = AGO.) que establecía el procedimiento civil aplicable al imperio austrohúngaro caracterizado por su escrituración, secretismo y sistema de prueba legal o tasada. En la actividad de litigación la recopilación de la información fáctica estaba asignada a un juez diferente del que tenía que decidir el caso ${ }^{15}$. Requería patrocinio letrado y se caracterizaba por un excesivo formalismo, sofisticadas disposiciones y un juez

${ }^{10}$ Frodl, Susanne, The Heritage of the Franz Klein Reform of Austrian Civil Procedure in 1895-1896, en Civil Justice Quaterly, 31 (2012) 1, p. 43; LANGER, Adalbert, Männer und die österreichische Zivilprozessordnung (Wien, 1895, reimpresión 1990), pp. 33-52.

${ }^{11}$ Sperl, Hans, Franz Klein t, en Zeitschrift für Zivilprozessrecht, 51 (1926), p. 407.

${ }^{12}$ Sperl, Hans, cit. (n. 11), p. 407.

${ }^{13}$ Rechberger, Walter, Die Ideen Franz Kleins und ibre Bedeutung für die Entwicklung des Zivilprozessrechts in Europa, en Ritsumeikan University Law Review (2008), pp. 102 ss.

${ }^{14}$ Rechberger, Walter, Die Ideen, cit. (n. 13), pp. 102 ss.

${ }^{15}$ LeOnhard, Otto, Zur Geschichte der österreichischen Justizreform vom Jahre 1898, en Gerö, J. (coordinador), Festschrift 50 jahre österreichischen Zivilprozessord- 
sin poderes que era en los hechos una pieza del juego cual herramienta más de las partes ${ }^{16}$. Como resultado los procesos tenían una excesiva duración el tiempo, el juez carecía de todo poder para coordinar el proceso y por ende era absolutamente irrelevante cualquier aspecto relacionado con la verdad, finalmente lograba triunfar la parte económicamente más fuerte y con mayor poder para influir en el caso. Debido a que el código establecía una especie de "référé législatif" frente a las dudas interpretativas, los tribunales tenían que solicitar una clarificación a la Corte Imperial. Ya transcurridos 15 años de emitido del código, se conformó un nuevo cuerpo codificado que contenía el conjunto de resoluciones interpretativas que se fueron adoptando inicialmente hasta configurarse luego el denominado "Código de la Galicia occidental" ("Wetsgalizische Gerichtsordnung") ${ }^{17}$. Como resultado de la aplicación de interpretación de las leyes por varios estados, cada vez más se necesitaba y exigía un código único y unificado. A ello se le suma la proliferación de ordenamientos procesales como la ley de procesos simplificados para causas de menor cuantía. Es importante destacar como durante el siglo XIX varios son los estados que a través de sus normas de organización orgánico-procesal intentan una unificación política del Estado (luego veremos cómo ello sucederá también con Alemania). Esta dispersión será parte del germen de las revoluciones y la intranquilidad generada en 1840 en los estados europeos ${ }^{18}$.

Debe mencionarse que las causas judiciales en materia civil se vinculaban normalmente con cuestiones de monto medio a elevado y con contiendas relativas al derecho de propiedad y sus ramificaciones para proteger al mismo de la arbitrariedad judicial ${ }^{19}$. Era lógico en ese esquema que el juez asuma un rol evidentemente pasivo y las partes eran literalmente las dueñas del proceso. Siendo una cuestión de naturaleza enteramente privada como era la existencia y alcances del derecho de propiedad, las partes no tenían cargas ni ningún deber de cooperación para con el tribunal a los efectos de dar prosecución y una pronta conclusión al proceso que habían iniciado. El juez carecía de todo poder para apercibirlas e instalarlas a que participen, declaren o presenten especialmente prueba documental ${ }^{20}$. Si es que la contraparte estaba en

nung (Wien, 1948), pp. 136 ss.; KLeIN, Franz - ENGeL, Friedrich, Der Zivilprozess Österreichs (Mannheim, 1927), p. 31.

${ }^{16}$ Sprung, Rainer, Die Ausgangspositionen österreichischer Zivilprozessualistik und ihr Einluss auf das deutsche Recht, en Zeitschrift für Zivilprozess, 92 (1979), pp. 4 y 7.

${ }^{17}$ KLEIN, Franz- Engel, Friedrich, cit. (n. 15), pp. 25-35.

${ }^{18}$ Rechberger, Walter, Die Ideen, cit. (n.13), p. 101.

${ }^{19}$ KLein, Franz, Zeit- und Geistesströmungen im Prozesse (Frankfurt a. M, 1943), pp. 3-5.

${ }^{20}$ Damrau, Jürgen, Der Einfluss der Ideen Franz Kleins auf den Deutschen Zivilprozess, en Hofmeister, H. (coordinador), Forschungsband Franz Klein (Wien, 1988), pp. 157 y 166. 
posesión de importante prueba, la contraparte precisaba iniciar un proceso independiente para ejercer su acción de restitución o exhibición a los efectos de poder solicitar dicha prueba documental. Ello terminaba encareciendo al proceso $y$, al depender uno de otro lo prolongaba innecesariamente ${ }^{21}$.

Debido a la necesidad de adecuación del derecho procesal a un derecho sustantivo ya existente como el código civil austríaco de 1812 era otro argumento más para instar la actualización de la herramienta orgánicoprocesal $^{22}$. Y justamente entre los años 1815-1873 empieza a sostenerse por parte importante de la doctrina la necesidad de la adecuación del "Código General" de justicia para poder cambiarlo a los paradigmas que significaban los principios de publicidad, oralidad, y libre valoración de la prueba ${ }^{23}$. Las necesidades y la sobrecarga del sistema de justicia se debían entre otras cosas al aumento y colapso de causas. Cada vez había mayor necesidad de acceder a la justicia ya no sólo por cuestiones de propiedad sino que se iban ampliando por la industrialización a materia social, laboral, y las incipientes relaciones de consumo ${ }^{24}$. Cada vez más se exigía una mejor, correcta, completa recopilación de los hechos y decisiones más oportunas en el tiempo. Ello ya había motivado el desarrollo de los procesos sumarios bajo el amparo del procedimiento denominado "bagatella" del año 1873 que dio lugar al de procesos sumarios del año $1845^{25}$. En el año 1874 se modifica el código General de la justicia atribuyendo al juez el poder y dirección de preguntas a testigos y de peritos continuando las partes con su derecho de interrogatorio. Ya varios sostenían que el rol del tribunal y su funcionamiento estaba en contravención con la ley fundamental del estado sobre el poder judicial ya que el juez carecía de autonomía e independencia para dirigir $Y$ conducir su despacho frente a las partes ${ }^{26}$. Durante los años 1879 A 1882 continuó ampliándose el rol social del Estado. Se extendió el derecho de voto al ámbito agrícola y a pequeños círculos de comerciantes los que comienzan a tener representatividad en el parlamento. Era la hora de comenzar a instalar un nuevo sistema de justicia civil que es defendido por un profesor de forma

${ }^{21}$ Sprung, Rainer, Der Lebensweg Franz Klein, en Hofmeister, Herbert (coordinador), Forschungsband Franz Klein (1854-1926). Leben und Wirken (Wien, 1988), XIII, pp. 15 ss.

${ }^{22}$ Sprung, Rainer, Franz Klein (24.4.1854-6.4.1926) Eine analysierende Lebensskizze, en Franz Klein Symposium (Wien, 2005), p. 7

${ }^{23}$ KLEIN, Franz, Die österreichischen Civilprozess-Gesetzentwürfe, en Zeitschrift für Zivilprozess, 19 (1893), p. 52.

${ }^{24}$ Hofmeister, Herbert (coordinador), cit. (n. 21), p. 67.

${ }^{25}$ Oberhammer, Paul - Domej, Tanja, Germany, Switzerland, Austria (ca. 18002005), en van Rhee, C.H. (coordinador), European Traditions in Civil Procedure (Antwerpen - Oxford, 2005), pp. 118 ss.

${ }^{26}$ KLEIN, Franz - ENGEL, Friedrich, cit. (n. 15), pp. 35-40. 
sistematizada y continuada mediante distintas publicaciones entre los años 1890 a 1891, era Franz Klein ${ }^{27}$.

\section{Pilares del nuevo proceso civil.}

En este contexto se encarga a Klein la redacción de un nuevo código procesal civil para Austria partiendo del Estado social de bienestar y con las premisas de que debía ser un código cuyos procedimientos sean fácilmente comprensibles, transparentes y que minimicen los costos de recurso humano y de tiempo. De esta forma el proceso asume en la visión de codificador un rol de herramienta política de contribución al bien común ${ }^{28}$. En base a tres principios se estructuró el nuevo código: $i$ ) las partes son las responsables del inicio y prosecución del proceso como así también del aporte de información fáctica y probatoria. Todo ello bajo la supervisión del juez revestido de potestades para la conducción del proceso y la facultad de requerir la cooperación de ambas partes para con el tribunal; $i$ ) una mejora en la celeridad del proceso; y iii) el proceso es un desarrollo colaborativo porque no sólo las partes por el principio dispositivo y de aporte probatorio, sino también el tribunal encarnaran una misión común, a saber llevar adelante un proceso para poder arribar a una solución fundada en justicia y verdad ${ }^{29}$. Las ideas plasmadas por el jurista fueron consideradas por algunos sectores como revolucionarias ${ }^{30}$.

En dos años concluyó la redacción del nuevo código procesal civil y fue puesto a disposición del parlamento en el cual se realizaron reformas de carácter menor, siendo finalmente aprobado en el año 1895 con promulgación del emperador y con entrada en vigencia en el año $1898^{31}$. No debe olvidarse que Klein también colaboró en la redacción de las normas orgánicas de los tribunales de 1896 como así también la Ley sobre el atribución y asignación de competencia de 1895 y el Código de ejecución de 1896, ello sin dejar de mencionar otros aportes del brillante jurista como por ejemplo la Ley de justicia juvenil y de prevención de la delincuencia redactada cuando era ministro de justicia ${ }^{32}$.

${ }^{27}$ Especialmente la influyente publicación de KLEIN, Franz, cit. (n. 3), pp. 10 ss.

${ }^{28}$ LeOnhard, Otto, cit. (n. 15), pp. 136 ss.

${ }^{29}$ KLEIN, Franz - ENGEL, Friedrich, cit. (n. 15), pp. 193-205.

${ }^{30}$ Véase, por ejemplo: Demelius, Ernst, Kritische Studien zu den Gesetzentwürfen aus dem Jahre 1893 (Wien, 1895), II; más detalles del impacto por las publicaciones de Klein en Hofmeister, Herbert (coordinador), cit. (n. 21), p. 67.

${ }^{31} \mathrm{BÄHR}$, Die neuen osterreichischen Civilprozess-Gesetzentwurfe, en Zeitschrift für Zivilprozessrecht, 19 (1894), p. 79; SPRUNG, Rainer, Franz Klein, cit. (n. 22), p. 7.

${ }^{32}$ Kralik, Winfried, Die Verwirklichung der Ideen Franz Kleins in der Zivilprozeßordnung von 1895, en HofMeister, Herbert (coordinador), cit. (n. 21), p. 89. 
Las nuevas demandas de justicia en el ámbito social y económico exigían un mayor y más fácil acceso a los tribunales de justicia, a lo que se sumaba la necesidad de una pronta respuesta ${ }^{33}$. Ello fue considerado por muchos en la época como un bien básico de la vida, especialmente de las clases menos pudientes $^{34}$. Debe recordarse la influencia de Anton Menger sobre Klein en su visión del trabajo conjunto del Estado para con los ciudadanos se fundaba en la necesidad de un proyecto conjunto y para el bien común ${ }^{35}$. Ello finalmente se traducía en la necesidad de una justicia civil abierta y accesible para todos los ciudadanos, no sólo en sus demandas relativas al derecho de propiedad y con elevada cuantía, sino también en las reivindicaciones económico sociales de las clases menos pudientes ${ }^{36}$. Así se facilita el acceso a la asesoría jurídica y a la justicia, el establecimiento de mecanismos para poder litigar en algunos casos sin costas o sin gastos, la ampliación y mejora de la asistencia legal y jurídica por parte del Estado para garantizar una igualdad de armas y de acceso a la jurisdicción ${ }^{37}$. Este fue el fundamento para sostener que no había razón para no dar cabida dentro del sistema judicial a los conflictos que surgían con la industrialización y la producción en masa, y que por ende ya no era suficiente un proceso sin que el Estado se involucrara activamente para un mejor, menos costoso y más efectivo resultado jurisdiccional ${ }^{38}$.

Como puede verse en este contexto se necesitaba no sólo una verdadera adecuación de los recursos humanos internos a la función jurisdiccional, a los efectos de mejorar la misión y visión de los tribunales y de los jueces individualmente en la gestión de los casos y la intervención activa en ellos, sino también el convencimiento de la comunidad y de las asociaciones de los abogados sobre las ventajas de un nuevo sistema. Había ya conciencia

${ }^{33}$ von ZeILler, F., Grundsätze über die Haupteigenschaften einer Civil-Gerichtsordnung, en Jährlicher Beytrag zur Gesetzkunde und Rechtswissenschaft, 3 (1808), p. 133; SpRUng, Rainer, Die Grundlagen des österreichischen Zivilprozessrechts, en Zeitschrift für Zivilprozessrecht, 90 (1977), pp. 380 y 387.

${ }^{34}$ Sprung, Rainer, Die Grundlagen, cit. (n. 33), pp. 380 y 387.

${ }^{35}$ Kralik, Winfried, cit. (n. 32), p. 89.

${ }^{36}$ Cfr. la propuesta en KLEIN, Franz, Gewahrte Freihaeit bei gewährter Hilfe (Freiburg (Breisgau) 1973), pp. 88-95; Hofmeister, Herbert, Franz Klein als Sozialpolitiker, insbesondere auf dem Gebiete des Privatrechts, Forschungsband Franz Klein (Wien, 1988), p. 203.

${ }^{37}$ Cfr. la obra de KLein, Franz, Die Schuldhafte Parteihandlung. Eine Untersucubung aus dem Civilprozessrechte (Wien, 1885), pp. 35-37; HofMEISTER, Herbert (coordinador), cit. (n. 21), p. 67.

${ }^{38}$ Bӧнм, Peter, Parteiautonomie versus Richtermacht; die Verantwortung für die Programierung des Verfahrensablaufes, en Bajons, Ena Marlis - BöHm, Peter - MariNELLI, Marino (coordinadores), L'attualità della reforma processuale e sociale di Franz Klein/ Die aktualität der Prozess- und Sozialreform Franz Kleins (Trento, 2011). 
que existirían limitaciones a conductas objetivamente abusivas y dilatorias a las cuales estaban acostumbrados y que de ahora en más se traducirían en posibilidad de sanciones. También que se instauraba desde ahora un trabajo colaborativo con el tribunal en la procura de una solución eficiente en términos de costo y de tiempo ${ }^{39}$, como así también cargas de cooperación dentro mismo del proceso para aportar información y prueba relevante, con la posibilidad en su defecto de aplicar sanciones probatorias o de carácter coercitivo. Un segundo aspecto consecuente del trabajo colaborativo y del nuevo rol asignado a las partes y sus abogados y al órgano jurisdiccional era de esperar una mayor celeridad en la función adjudicativa ${ }^{40}$. En otras palabras los procesos no necesitarían más de un exceso de tiempo para arribar a una solución justa, sino sólo aquella duración que era necesaria, esto de alguna forma iba a tener una repercusión en la productividad y en la economía del mercado al trabajarse con costos de transacción previsibles en su monto y en el tiempo ${ }^{41}$. La necesidad de un proceso con duración adecuada en el tiempo se fundaba en la limitación de los recursos humanos e infraestructurales de la propia función jurisdiccional como así también en la necesidad de que puedan acceder a la justicia la mayor cantidad de casos posibles, para obtener la mayor cantidad de resoluciones de conflictos lo más justa y oportunamente posible. Así se vinculaba el costo el tiempo y lo justo y correcto de resultado jurisdiccional ello se complementaba con la innecesaria edad en algunos casos de patrocinio letrado, como ser las cuestiones de menor cuantía ${ }^{42}$.

Relacionado con este primero y el segundo principio se establecen finalmente sanciones y mecanismos concretos de imperativos de lealtad y de veracidad procesal a los efectos de que se logren evitar litigios posteriores sobre cuestiones que ya fueron conocidas y decididas. Era a partir de una correcta decisión que per se tenía una fuerza tal de legitimada y de legitimación que iba a ser observada y acatada sin generarse posteriores litigios en torno a la misma. Ello se fortalecía con imposiciones de conducta de colaboración en las partes, sus representantes, en algunos casos deberes de comparecencia personal, posibilidades de actuaciones probatorias de oficio por parte del tribunal, y normas de preclusión con un juego sistémico del principio de eventualidad procesal. Es decir, se tendía a la organización por audiencias en las que se establecían tareas concretas y preestablecidas y donde las partes

${ }^{39}$ Bӧнм, Peter, $\mathrm{Zu}$ den rechtstheoretischen Grundlagen der Rechtpolitik Franz Kleins, in Hofmeister, Herbert (coordinador), cit. (n. 21), p. 191 y 200.

${ }^{40}$ Oberhammer, Paul, Richtermacht, Warheitspflicht und Parteienvertretung, en KRALIK - Rechberger (coordinadores), Konfliktvermeidung und Konflicktregelung (Wien, 1983), p. 31; cfr. BECKER-Eberhard, Ekkehard, cit. (n. 6), pp. 15, 32 ss.

${ }^{41}$ KLeIN, Franz, Zeit- und, cit. (n. 19), pp. 21-28.

${ }^{42}$ Ibíd., p. 14. 
podían realizar sus alegaciones cerrándose la posibilidad de volver sobre las mismas en etapas posteriores oportunidad, inadmisibilidad y en casos extremos invalidación (imposición del principio de eventualidad) ${ }^{43}$.

\section{El PROCESO CIVIL ALEMÁN y LA Figura DE Adolf WACH}

Adolf Wach nació el 11 de septiembre de 1843 en el este prusiano en una ciudad que marcó su personalidad donde una mitad de la población era alemán y la otra polaca. Familia de religión protestante y espíritu liberal que se forjó en sus estudios básicos y medios en el gimnasium, donde casi la mitad o más eran polacos católicos. Él mismo relata la anécdota de cuando en la escuela le preguntaron sus compañeros si era alemán o católico a lo cual respondió ser evangélico ${ }^{44}$. Estudió derecho inicialmente en la Universidad Libre de Berlín luego en Heidelberg por un corto período que fue importante en su formación ya que integro la cofradía Alemania a la cual pertenecían por entonces importantes pensadores como Max Weber ${ }^{45}$. Estudió luego en Leibniz en la Albertus Universidad donde trabajó en el área de derecho canónico y obtuvo su doctorado sobre el juramento provistos. Allí fue que recibió una importante influencia del jurista Sanio que lo impulsó a que posteriormente habilitara en 1868 en Göttingen sobre la historia del embargo italiano y alemán. Su habilitación se concentró en la historia del proceso de embargo italiano, texto que trató sobre los procedimientos sumarios, procedimiento ejecutivo y detalles del marco histórico. De allí se desempeñó como libre docente hasta que recibió el llamado para convertirse en profesor ordinario en Rostock con 26 años en 1869. Luego recibiría el llamado de la Universidad de Tübingen ya en 1871 donde se desempeñó como ordinario e integró una cofradía de la cual pertenecían importantes pensadores como el procesalista Oscar Büllow. Entre 1872 a 1876 se desempeñó como ordinario en Bonn donde tuvo especial contacto con Bethmann-Hollweg (1795-1877) quien delegó en él continuar su obra sobre el proceso civil del derecho común en su desarrollo histórico ${ }^{46}$. Entre 1876 y 1920 se desempeñará como profesor

${ }^{43}$ Sobre el desarrollo coherente posterior del ZPO. austríaco véase: FASCHING, Hanns W., Die Weiterentwicklung des österreichischen Zivilprozessrechts im Lichte der Ideen Franz Kleins, en HofmeISTER, Herbert (coordinador), cit. (n. 21), p. 101-102; sobre la influencia del ideario de Klein en Italia puede verse: KöNIG, Bernhard, Die österreichische Zivilprozessordnung und das Königreich Italien, en Juristische Blätter (1981), p. 585.

${ }^{44}$ Unger, Dagmar, Adolf Wach (1843-1926) und das liberale Zivilprozessrecht (Berlin, 2005), passim.

${ }^{45}$ ScHмIDT, Adolf Wach, en Zeitschrift für Zivilprozessrecht, 100 (1987), p. 3.

${ }^{46} \mathrm{~W}$ ACH, Adolf, Wie Ich Jurist wurde? en Deutsche Juristenzeitung, 14, (1919), p. 1008. 
ordinario en la Universidad de Leipzig, integrará diferentes asociaciones y fundaciones con fines culturales y consejos académicos. Fue miembro también de la asociación de derecho procesal civil que nace en el año 1920. Concluye su carrera pensionándose en 1919 en la Universidad de Leipzig. Fallece el 4 de abril de 1996.

\section{La codificación del proceso civil alemán de 1877.}

El proceso civil alemán en el siglo XIX asumirá una característica importante desde el punto de vista político. Sus antecedentes son variados y dispersos, solo recuérdese que el imperio no era tal y que existía una división y mosaico territorial en distintos reinos con variados antecedentes históricos en ciertos casos, incluso en lo procesal. Algunos con notable influencia del derecho francés en el oeste, otros con influencia más germana e itálica en el caso de los reinos prusianos. De allí que convenga hablar no sólo del código procesal civil del imperio de 1877, sino de un código dentro de un marco cual era la unificación del imperio a través de la unidad de la justicia como poder del estado: en lo orgánico, en lo procesal civil, procesal penal, e insolvencia que permita reconstruir lo disuelto luego de la derrota frente a Francia en el año 1806. Ya a mitad del siglo XIX pueden mencionarse la existencia en Alemania de al menos tres grandes regiones en materia procesal civil: aquellas en las cuales regía el proceso civil francés, las que estaban bajo el proceso prusiano y finalmente las sujetas al proceso común.

No en vano se constituye una comisión en 1862 que elaborará el proyecto de código procesal civil de Hannover el que adoptaba no sólo la oralidad, sino también el principio o máxima de eventualidad, es decir la imposibilidad por la preclusión de incorporar nuevos hechos por las partes luego de la primera etapa del proceso hasta la dictación de la sentencia definitiva. Esta división del proceso en dos etapas bien marcadas con el juego sistemático de la eventualidad y la oralidad era desconocida y extraña al derecho francés, el que más bien trabajaba con un proceso unificado sin etapas ni efecto preclusivo que impidiera aportar nuevas alegaciones en faces procesales avanzadas y cercanas al momento de la dictación de la sentencia definitiva. El otro sistema era el de los estados nórdicos federados que impulsaban la necesidad de la unidad política a través de la unificación de los procesos judiciales que produjo su propio proyecto de proceso civil para los estados federales nórdicos en 1870 muy similar al proyecto de Hannover pero con un sin número de reservas. Una vez concluida la guerra en 1870 los estados del sur elaboraron un proyecto que fue publicado en 1871 , denominado proyecto ministerial o Primer Proyecto que difería en algunos aspectos en relación al proyecto de los estados nórdicos federados. Su característica estaba dada en el ideal que implicaba la oralidad, la pasividad del juez como así también el 
dominio y manejo de las partes sobre el proceso. Como se hace notar en los antecedentes, se parte del principio deliberativo y del aporte de parte como así también del pleno principio dispositivo. Desconocía cualquier aplicación del principio de eventualidad o de preclusión a la posibilidad de aporte de hechos por las partes en sus aplicaciones hasta la sentencia de mérito. Este primer proyecto fue trabajado por una comisión de juristas dando lugar a lo que se denominó el "Segundo Proyecto". Éste sería aprobado por el Bundestag con algunas modificaciones al igual que el código procesal penal y a las leyes introductorias lo que fue aprobado en 1877 entrando en vigencia en el año 1879. El pensamiento fundamental del Código Procesal Civil del Imperio fue su acercamiento al proceso civil francés, vigente al oeste del Rin totalmente diferenciado del proceso común como así también de las influencias del proceso civil prusiano. Rige fuertemente la oralidad, no existen imperativos de protocolización, sólo es relevante y tiene importancia para la decisión del proceso aquello que es alegado y discutido en forma oral. De esta forma el juez que conoce debía remitirse a lo que había sido materia tratada en las audiencias primando sobre los escritos de las partes. Así aquello que fue agregado por escrito y no confirmado en forma verbal ni discutido en las audiencias, no podía ser considerado al momento de la sentencia y de la decisión. La inversa de "quod non est in acta non est in mundo" 4 .

Era considerado un código de tinte liberal donde la libertad y el dominio de las partes primaba en su visión sobre cualquier impulso por parte del tribunal o cualquier tipo de "intromisión por parte del Estado" se manifestaban en la solución de los conflictos a través del proceso civil ${ }^{48}$. Así en los hechos el Estado y la Judicatura no tenían ningún tipo de interés en la corrección y justicia de la sentencia que se pronunciaba. En consecuencia la determinación de la verdad era ajena como finalidad al proceso; el resultado y la sentencia correcta, acorde a la verdad era apenas una consecuencia accidental, lo que justificaba el rol pasivo del tribunal. Éste no debía intervenir en la lucha entre las dos partes y correspondía que otorgara la razón mediante su sentencia a quien resultara formalmente victorioso, sin tener relevancia la calidad de lo decidido ${ }^{49}$. El tribunal no solamente tenía las características de independencia y de imparcialidad sino también no debía asumir ningún rol dentro del proceso so consecuencia de convertirse en parte interesada del

${ }^{47}$ Schilbach, Luisa-Carlota, Die Wesentlichen Grundzüge der Geschichtlichen Entwicklung des ordentlichen prozesses (Heidelberg, 1937), pp. 5 ss.

${ }^{48}$ De Boor, Hans Otto, Rechtstreit einschliesslich Zwangsvollstreckung (Berlin, 1940), pp. 28 ss.

${ }^{49} \mathrm{WACH}$, Adolf, Vorträge über die Reichs-Civilprocessordnung, gehalten vor praktischen Juristen im Frühjahr (Bonn, 1879), p. 149. 
mismo (dejaba de ser "Impartial") ${ }^{50}$. Así el proceso respetaba formalmente principios orgánicos, se contentaba apenas con la llamada verdad formal y de esta forma se mantenía incólume el dominio ilimitado de las partes sobre el proceso y sobre su dinámica como manifestación máxima del principio deliberativo y dispositivo ${ }^{51}$.

\section{Wach y la reforma al proceso civil austriaco.}

Es posible encontrar al menos tres puntos de diferencia en torno a las codificaciones del proceso civil austríaco y alemán. En primer lugar debe aclararse que el pensamiento liberal y las ideas sobre el rol del Estado, de los tribunales, la libertad y disposición de las partes sobre el proceso fueron temas apenas discutidos en la codificación alemana. Recién serán objeto de atención con el correr de los tiempos y en sucesivas reformas especialmente durante los primeros 20 años del siglo $\mathrm{XX}^{52}$. El código alemán no se ocupó de establecer mecanismos eficientes para enfrentar la conducta dilatoria del proceso, teniendo especialmente en cuenta el rol asignado a las partes por sobre el tribunal. No existía un correlato de sanción en la responsabilidad de las partes por la conducción del proceso ${ }^{53}$. En segundo lugar la influencia del Estado en la vida social y económica fue creciendo con la creciente industrialización, lo que tuvo por resultado, de la misma forma que en Austria un aumento y sobrecarga del sistema de justicia civil, que va a impulsar una serie de reformas ya en la primera década del siglo $\mathrm{XX}^{54}$. La implantación de la oralidad, publicidad, inmediación y libre valoración de la prueba no podían quedar al margen del rol del proceso judicial dentro del Estado y de la sociedad de derecho. La visión liberal de la neutralidad y de la inocuidad del proceso no se correspondía con los tiempos que ya se estaban por vivir y se vivirían especialmente en el siglo XX con la Primera Guerra Mundial. El tercer aspecto relevante fue la eliminación de todo principio de eventualidad y de preclusión, no por sí mismos sino fundado en el dominio y disposición de las partes sobre el proceso como algo propio y la consecuente pasividad requerida del tribunal ${ }^{55}$. A finales del siglo XIX y comienzos del siglo XX se empieza a difundir la denominada visión social del proceso, entendiendo que el sistema de administración de justicia no es neutro. Por el contrario

${ }^{50}$ De Boor, Hans Otto, Die Auflockerung des Zivilprozesses (Tübingen, 1939), p. 25.

${ }^{51}$ Sprung, Rainer, Die Ausgangspositionen, cit. (n. 16), pp. 5-8.

${ }^{52} \mathrm{KISCH}$, Guido, Adolf Wach und die österreichise Rechtswissenschaft (s.l., 1926), p. 5

${ }^{53}$ Sellert, Wolfgang, Die Reichjustitzgesetze von 1877, Ein gedenkwürdiges Ereignis? en Juristische Schulung (1977), p. 781-789.

${ }^{54}$ Oberhammer, Paul - Domej, Tanja, cit. (n. 25), pp. 118 ss.

${ }^{55}$ Wach, Adolf, Die Novelle zur Civilprozessordnung, en Deutsche Juristen Zeitung, 4 (1898), p. 65. 
desempeña un rol dentro de la sociedad y del Estado para la consecución del bien común como un servicio mediante el cual se garantiza el correcto andamiaje de la economía privada en una sociedad organizada. El correcto, oportuno y adecuado funcionamiento de las instituciones de la justicia es un presupuesto para el devenir y dinámica de la sociedad y del Estado ${ }^{56}$. De esta forma la visión de la finalidad y utilidad del proceso civil para el desarrollo de la sociedad, la eliminación de obstáculos para el acceso a la justicia y la garantía de acceso de los más imposibilitados merecen un sistema de protección del Estado ${ }^{57}$. Estas fueron las principales críticas frente al nuevo código procesal civil alemán en comparación con la gran reforma que estaba llevando adelante Austria. Interesan una serie de publicaciones iniciales de Wach de fines del siglo XIX y otras posteriores durante el siglo XX que fueron importantes para las reformas que se llevaron a cabo al código procesal civil alemán original del imperio de 1877.

Un primer artículo es aquel relacionado con la oralidad en el proceso civil austríaco que justamente surge de una conferencia en Viena. En él se esboza la posición de Wach contrario a lo que él denominaba la escolástica y el dogmatismo de la oralidad proponiendo un sistema intermedio, ni el extremo del deber de protocolización del proyecto austríaco, ni la falta absoluta de registro $^{58}$. Un segundo aporte relevante será su informe en derecho del año 1902 para el $26^{\circ}$ Congreso de Juristas Alemanes sobre las limitaciones del derecho judicial y el impulso de parte en el proceso civil ${ }^{59}$. El tema de dicho informe se relacionaba con la pregunta sobre si el impulso de parte tal cual está planteado en el código procesal civil alemán servía en forma verdadera, saludable y oportuna a una justa tutela jurídica de los derechos de las partes. Si se garantizaba así un correcto y legal proceso o si bien debía fortalecerse el principio de dirección judicial en cabeza del juez del proceso (oficialidad). En términos prácticos se pronuncia para el Código Procesal Civil Alemán vigente sosteniendo que podría conducir de futuro (como así aconteció) con la exacerbación del impulso de parte frente a la oficialidad a un estancamiento o entorpecimiento del proceso civil ${ }^{60}$. Sostenía en primer lugar que el proceso integra la función de resguardo y protección de los derechos por parte del Estado y está dominado por su interés por el buen funcionamiento de la

${ }^{56}$ Véase al respecto: KLEIN, Franz, Civilprozess-Gesetzentwürfe, en Zeitscherift für Zivilprozessrecht, 19 (1893), p. 36.

${ }^{57} \mathrm{WACH}$, Adolf, Der Rechtsschutzanspruch, en Zeitscherift für Zivilprozessrecht, 32 (1904), pp. 9-10.

${ }^{58} \mathrm{WACH}$, Adolf, Die Mündlichkeit in dem Entwurf der Österreichischen Zivilprozessordnung (Wien, 1895), p. 17.

${ }^{59}$ W ACH, Adolf, Verhandlungen des 26 DJT (Berlin, 1902), II, pp. 3-31.

${ }^{60} \mathrm{WACH}$, Adolf, Verhandlungen, cit. (n. 59), pp. 4-8. 
Justicia y la idoneidad de los medios establecidos para conseguirlo ${ }^{61}$. Así de ninguna manera la dirección oficiosa del proceso se superpone y elimina la disposición de las partes sobre el objeto litigioso, sino más bien debe entenderse que el proceso no es una simple convención y que las partes no establecen la forma y orden de cómo se lleva adelante, como podría suceder en un proceso arbitral. Más bien se origina en la voluntad misma del Estado, su capacidad de adecuación de la función jurisdiccional para el resguardo de los derechos de acuerdo a un fin elevado y superior ${ }^{62}$. Se hace así necesario un equilibrio en la regulación del poder y dominio de las partes y del juez sobre el proceso para evitar la demora, dilación como así también el manejo del proceso por la sola voluntad de los intereses de las partes en detrimento de los recursos públicos existentes del Estado. La duración necesaria del proceso debía tener un reflejo en mecanismos que incentiven la dinámica procesal entre otros con sanciones en materia de costas. Por ejemplo mediante la generación de consecuencias negativas sea en lo probatorio, sea en el régimen de costas para aquel que haga mal uso de la institución. Concluye finalmente en que la exageración del principio dispositivo, tal cual está concebido actualmente en el código tiene consecuencias negativas fundamentalmente en la traba y en la demora de los procesos, es por ello que debe ser limitado por el principio de oficialidad ${ }^{63}$. Debe otorgarse al juez una mayor responsabilidad de cooperación para el impulso y la dirección del proceso ${ }^{64}$.

Otro aporte importante será el artículo que publica en el año 1914 sobre las preguntas fundamentales y la reforma al proceso civil. En él se pronuncia sobre el rol de la verdad en tanto finalidad del proceso y como un punto central de las futuras reformas. Parte por aceptar la importancia de la verdad formal y sosteniendo que el proceso no tendría como finalidad por sí la obtención de la verdad material. Esto debía comprenderse en tanto el rol que desempeñaba la verdad como una fraseología teórica ya que no podía imponerse a las partes ni a sus representantes un deber de veracidad absoluto. Ello ya que bastaba la ética y deberes profesionales de investigación limitados por sus intereses y un deber público de no mentir y llevar adelante una conducta conforme al honor y al buen conocimiento no contrario al derecho y a la verdad ${ }^{65}$. Así fundamentó las reformas en tres ámbitos importantes. Primeramente se debían eliminar los excesos e inútiles formalismos que retardan y quitan fuerza al proceso, luego se debía dotar al juez de herramientas

\footnotetext{
${ }^{61}$ Véase por cierto: GotTwald, Peter, cit. (n. 9), pp. 180 ss.

${ }^{62} \mathrm{WACH}$, Adolf, Verhandlungen, cit. (n. 59), pp. 65-68

${ }^{63}$ Ibíd., pp. 20-32.

${ }^{64}$ Ibíd., 608-611.

${ }^{65} \mathrm{WACH}$, Adolf, Grundfragen und Reform des Zivilprozesses, (Berlin, 1914), pp.
} 78-101. 
tales que garantice un proceso con dinámica y control en la dirección del mismo, finalmente se debía fortalecer inmediación. El impulso y poder de dirección por el tribunal quedaba morigerado por el reconocimiento a las partes de sus derechos, sí no en términos de dominio absoluto del proceso o de "propiedad" de éste ${ }^{66}$. Debía minimizarse el dominio absoluto de las partes con un adecuado control del juez, especialmente en las notificaciones para evitar arbitrariedades. El tribunal no debía comportarse en forma pasiva, sino por el contrario ser un activo interviniente para evitar vicios y rechazar aquellas alegaciones que eran innecesarias. La etapa inicial de intercambio de escritos debía ser dirigida por el tribunal evitándose y controlando éste la oportunidad, eliminándose la demora y rechazando de oficio una vez concluida todos aquellos aportes tardíos que realizaran las partes. También consideró relevante el establecimiento de una audiencia preparatoria o preliminar en la cual se permitan solucionar las causas no complejas más rápidamente e instando a las partes para que arriben a un acuerdo. Finalmente era necesario, según su opinión la sanción en costas de la parte responsable de la demora o arbitrariedad en el proceso y en tanto responsabilidad objetiva sin consideraciones a factores subjetivos de atribución ${ }^{67}$.

\section{LA INFLUENCIA DE LOS PRINCIPIOS PROCESALES De Austria y Alemania en el proceso civil fRANCÉS}

Puede sostenerse que el (nuevo) Código Procesal Civil francés con la gran reforma de 1975 es un código de carácter doctrinal. Las ideas bases sobre proceso y litigación civil pueden ser analizadas a través de los primeros veinticuatro artículos del código que constituyen a su vez el primer capítulo integrado por los principios procesales ${ }^{68}$. Debe recordarse que el código original de 1806 es herencia del liberalismo decimonónico y seguía la tradición francesa. Sí fue paulatinamente modificado durante el siglo XIX por la visión de la función social del proceso de influencia austro-alemana especialmente entre 1862 a $1925^{69}$.

La idea base contenida en los principios generales del proceso se fundan

${ }^{66}$ Wach, Adolf, Grundfragen, cit. (n. 65), pp. 87-95.

${ }^{67}$ Ibíd., pp. 104-112.

${ }^{68}$ CADIET, Loï, Introduction to French Civil Justice System and Civil Procedural Law, en Ritsumeikan University Law Review (2011), p. 331; Wijffels, Alain, French Civil Procedure (1806-1975), en van RHEE, C.H. (coordinador), European Traditions in Civil Procedure (Antwerpen - Oxford, 2005), pp. 25-47.

${ }^{69}$ CADIET, Loï, The International Sources of French Civil Procedure, en DEGUCHI, M. - Storme, M. (editores), The Reception and Transmission of Civil Procedural Law In The Global Society (Antwerpen - Apeldoorn, Maklu, 2008), pp. 261-274. 
no exclusivamente en una visión del proceso como cuestión de las partes, ni tampoco en la actividad dominantemente inquisitiva por parte del tribunal, sino más bien como una visión de sociedad o comunidad entre el juez y las partes. "Sociedad" en la que se impone una permanente colaboración en la determinación del objeto litigioso como así también para el impulso y prosecución del proceso. También exige una racional distribución de responsabilidades entre las partes y el tribunal, como lo enuncia el código: el principio de una eficiente cooperación entre el juez y las partes ${ }^{70}$. Ello es visto y fue en su momento considerado como una manifestación de la gestión y dirección coordinada del proceso y de los casos en tiene que ser eficiente y equitativa en consonancia con el principio 11.2 de los principios trasnacionales del proceso civil.

Téngase presente que la gran reforma durante el siglo XX en la década de los 70 tienen correlación con el artículo 37 de la entonces nueva Constitución francesa que otorgaba directamente competencia al ejecutivo para legislar en materias de proceso civil. Reforma por cierto introducida para evitar las demoras parlamentarias, órgano dominado en ese entonces por abogados. El nuevo código procesal civil fue concebido como la culminación de reformas sustanciales que fue experimentando paulatinamente entre 1963 a 1981 . Uno de los principales mentores de la incorporación de este conjunto de principios procesales que dan su tinte doctrinal al código fue Henry Motulsky ${ }^{71}$. Todo comenzó en 1963 cuando se comenzó a trabajar sobre el nuevo código con el advenimiento del profesor Jean Foyer ya antes de ser designado ministro de justicia entre 1963 a 1968 quien convocó a una importante comisión de juristas para la reforma del proceso civil existente. Ya mediante el decreto número 65-872 del 13 de octubre 1965 se estableció un mecanismo piloto consistente en la gestión de casos bajo la dirección procesal del juez ante el tribunal de gran instancia o los tribunales que sustituían a los de primera instancia ${ }^{72}$. El mecanismo denominado "mise en état" (versión ciertamente asimilada a la gestión de casos, con ciertas reservas) tenía relación con la importante reforma judicial en Francia del año 1958. Fueron justamente una serie de artículos doctrinarios que influyeron notablemente en aquello.

${ }^{70} \mathrm{Jeuland}$, Emmanuel, La conception du procès civil dans le Code de procédure civile de 1975, en Cadiet, L. - CANivet, G. (editores), 1806-1976-2006, de la commémoration d'un code à l autre: 200 ans de procédure civile en France (Paris, 2006), pp. 101 ss..

${ }^{71}$ Bolard, G., voz "Motulsky (Henri)", en Cadiet, L. (coordinador), Dictionnaire de la Justice (Paris, 2004); CoRnu, G., L'avènement du nouveau Code de procédure civile. La codification, en COUR DE CASSATION (coordinador), Le nouveau Code de procédure civile: vingt ans après (Paris, 1998), pp. 19-28.

${ }^{72}$ Cornu, G. - Foyer, J., Commentaire de la Réforme judiciaire (22 décembre 1958) (Paris, 1960), pp. 12-13. 
Así sobre el influyente artículo de Motulsky de 1871 sobre los prolegómenos del futuro código de proceso civil y los principios directrices del proceso ${ }^{73}$. Previamente ya se había publicado un comentario al decreto de 1965 relacionándolo con la necesidad de introducir los principios guías del proceso $\operatorname{civil}^{14}$. Debe sí mencionarse que la tarea asumida por la Comisión para la elaboración del código fue un trabajo gradual y en detalle desde lo primero hasta lo último a través de la competencia legislativa delegada al ejecutivo para hacerlo mediante decretos ${ }^{75}$. No obstante el nuevo código de 1975 aún hacía referencia al antiguo de 1806 el que quedó expresa y específicamente derogado recién por la reforma del año 2007.

La idea de comenzar el código con una serie de principios generales no era nueva, de hecho había sido ya discutida en la codificación napoleónica. En materia procesal aparece por primera vez la expresión "principios" en 1932 con el libro publicado de René Morel, el tratado elemental de proceso civil ${ }^{76}$. Éste había hecho en realidad una traducción libre de los principios procesales que regían en el proceso civil alemán para retomarlos como principios guías del proceso civil francés. Según lo sostiene Cadiet es justamente la tesis de Henri Motulsky titulada Principes d'une réalisation méthodique du droit privéla que influyó en mayor grado. La concepción austro-alemana sobre los principios procesales fue receptada también y de esta forma se incorporaban principios como los de iniciativa e impulso procesal ${ }^{77}$ y la imposibilidad de que el tribunal falle más allá de las alegaciones realizadas por las partes y que hayan sido discutidas en el proceso. Es posible sostener que fue esta obra fuente primaria del nuevo código procesal civil ${ }^{78}$. Los principios que se consagran están relacionados con el procedimiento judicial, las materias sujetas a conocimiento, los hechos, la prueba, el derecho, el procedimiento adversarial, la defensa, la conciliación, las alegaciones orales y el deber de restricción o de decisión de acuerdo a lo conocido o alegado por las partes.

${ }^{73}$ Motulsky, Henry, Prolégomènes pour un futur Code de procédure civile: la consécration des principes directeurs du procès civil par le décret du 9 septembre 1971 (Paris, Dalloz, 1972), Chronique, XVII, en Motulsky, H., Ecrits, I : Études et notes de procédure civile (Paris, 1973), p. 275-304.

${ }^{74}$ Connu, G., L'élaboration du Code de procédure civile, en Revue d'histoire des facultés de droit et de la science juridique (1995), p. 241; PARODI, C., L'esprit général et les innovations du Nouveau Code de procédure civile, en Defrénois (1976), pp. 673 ss.

${ }^{75}$ Motulsky, H., Ecrits, cit. (n. 73), pp. 130 ss.

${ }^{76}$ Morel, René., Traité élémentaire de procédure civile (2a edición, Paris, 1949), p. 345-348.

${ }^{77}$ Rounette, G., L'influence en France de la science allemande du procès civil et du Code de procédure civile allemand, en HABSCHEID, W.J., Das deutsche Zivilprozessrecht und seine Ausstrablung auf andere Rechtsordnungen, (Bielefeld, 1991), p. 159 ss.

${ }^{78}$ Cornu, G. L'avènement du nouveau Code, cit. (n. 71), pp. 19-28. 
Se establece el principio de contradicción que es en realidad -la forma de traducir lo adversarial- y el principio de publicidad como así también la asignación de roles y responsabilidades a las partes y al tribunal a los efectos de una colaboración racionalizada y coordinada entre estos. Debe mencionarse que este conjunto de distribución de roles entre el juez y las partes no es de ninguna manera un modelo de intervención de oficialidad o inquisitivo ${ }^{79}$ menos uno autoritario ${ }^{80}$. El código es esencialmente una propuesta de síntesis no extremadamente adversarial, no extremadamente inquisitorial, los que no son aplicables por si solos para calificarlo. Es más bien una conciliación de los principios existentes en la tradición francesa que enarbola al proceso como perteneciente a los intereses de las partes y la afirmación de los poderes del juez quien debe como mandato o imperativo de su función procurar la dirección del proceso para arribar a una solución justa de la controversia. Ello a sabiendas que repercute o termina generando efectos en el interés general de la sociedad. La justicia es un servicio público y la imparcialidad no se confunde con la pasividad ${ }^{81}$.

En efecto entre los artículos 1 al 13 del nuevo código se define un verdadero principio de cooperación entre el juez y las partes en la elaboración, dirección y prosecución, como así también conclusión de un proceso mediante un pronunciamiento judicial. De acuerdo a la tradición francesa, no obstante ser el proceso un negocio de las partes, constituye un servicio público y por ello fundado en que el juez debe intervenir colaborativamente con las partes para lograr obtener la solución más justa posible. Ciertamente el tribunal tiene las potestades para la conducción del proceso de forma que se asegure su prosecución y la concentración sobre las materias objeto de controversia. Ello permite una mejor organización y administración del tiempo, imponiendo a las partes la colaboración y pudiendo el tribunal tanto imponer medidas coercitivas, como interpretar la conducta de las partes cuando estas se muestran renuentes a cooperar. El principio de contradicción o el contradictorio contiene el tradicional principio adversarial, es decir el derecho a que las partes sean oídas en sus alegaciones. Ello como imperativo del artículo 6 inciso primero de la Convención Europea de derechos humanos. El código combina procedimientos donde la oralidad se mezcla con la escrituración, no hay un procedimiento declarativo único, sino que se adecuan flexiblemente a la materia litigiosa que se discute. Hay también alternativas procesales de carácter provisional y rápidos para evitar que la duración normal de los procesos afecten la obtención de justicia ${ }^{82}$.

\footnotetext{
${ }^{79}$ Motulsky, H., Prolégomènes, cit. (n. 73), pp. 275-304.

${ }^{80}$ C. Parodi, cit. (n. 74 ), pp. 673 ss. ; G. Cornu, L'élaboration, cit. (n. 74 ), p. 241

${ }^{81}$ Cadiet, Loïc-Jeuland, Emmanuel, Droit judiciaire privé(Paris, 2013), pp. 40-43.

${ }^{82}$ Cadiet, Loï - Normand, Jacques - Amrani Mekni, Soraya, Théorie générale
} 


\section{Respuesta A UN FAlso Dilema: ¿EFICIENCIA Y EFICACIA VS. GARANTISMO?}

Se puede constatar que el fenómeno de la "publicitación" o "socialización" del proceso, en especial durante el siglo XX con la influencia de la codificación austríaca y las reformas en el proceso civil alemán, tuvo por consecuencia no excluir ni anular el principio dispositivo, sino más bien más bien unirlo conjuntamente con el principio de deliberación, discusión de las partes y el rol adecuado del juez. Se logró arribar a un perfectible equilibrio entre las responsabilidades asignadas a las partes y al juez dentro del proceso ${ }^{83}$. Como parte de ello y la revalorización del tiempo junto con la minimización de costos es que en toda las funciones públicas del Estado se establecen ciertos parámetros de celeridad y oficiosidad para impedir justamente que los recursos escasos aplicados para un caso en concreto queden sujetos a la sola arbitrariedad del o de los interesados considerando la existencia de otros casos posibles ${ }^{84}$.

Las partes nunca pierden su poder de disposición sobre lo que es el objeto del proceso y sus intereses en juego. Sí no pueden utilizar al proceso como una propiedad o instrumento sujeto a su solo interés para configurarlo. En tanto función pública del Estado la función jurisdiccional y el valor justicia, ello es la ponderación en oportunidad y corrección de las decisiones son inseparables. La justicia como valor supone que los intereses en juego, la información que se aporta y eventualmente la prueba que llega a producirse girará en torno a lo que podría llegar a considerarse acorde a lo verdadero, con toda las salvedades y limitaciones del valor verdad ${ }^{85}$. Ello es lo que justifica entre otras cosas que el juez tenga la posibilidad de ciertas potestades de dirección y de impulso del proceso, cuando no también la posibilidad de desempeñar un rol también responsable en la actividad probatoria ${ }^{86}$.

\section{Garantismo y garantías sobre todo: distorsiones históricas y conceptuales.}

Es curioso como este fenómeno de la "publicitación" del proceso civil

du process (Paris, 2010), p. 192 ss. sobre la denominada "contractualización” del proceso civil y el rol cooperativo de partes y tribunal.

${ }^{83}$ CADIET, Loïc, Introduction, cit. (n. 68), pp. 340 ss.

${ }^{84}$ Magendie, J.-C., Célérité et qualité de la justice. La gestion du temps dans le procès, en La documentation française (Paris, 2004), pp. 20-35..

${ }^{85}$ van Rhee, C.H., Civil Justice in Pursuit of Efficiency, en UzELAC (coordinador), Goals of Civil Justice and Civil Procedure in the Contemporary World (New York - London, 2014), pp. 61 ss.

${ }^{86}$ Véase al respecto y relacionado con la economía procesal como sustento de la necesidad de cooperación: BRÄNDLI, Beat, Prozessökonomie im schweizerischen Recht (Bern, 2013), pp. 150 ss. 
de forma tal que llega a sincerarse con una función pública y propia del Estado de derecho es tomada por algunos como una mera visión política pre-formulada y acorde a paradigmas pétreos ya anacrónicos. Sólo mencionar los aportes de Cipriani ${ }^{87}$ y Monteleone ${ }^{88}$ en Italia Alvarado Velloso ${ }^{89}$ en Argentina, Montero Aroca ${ }^{90}$ en España. Es también curioso constatar cómo los aportes comunes de estas visiones son calificar de totalitarias o de fascistas a los aportes realizados especialmente por Klein y el ZPO. alemán. Puede según lo detallado restar valor científico a dichas críticas en tanto simples calificativos que no se coinciden con lo que fue la realidad histórica y menos el producto legislativo al que se arribó. Como se ha visto muy por el contrario el fenómeno de la publicitación del proceso trajo aparejado el elevar una cantidad de meros requerimientos a la calidad de garantías y derechos fundamentales de carácter procesal. Simplemente se reitera una discusión que como vimos fue la misma generada en torno a los aportes de Klein y las que se dieron dentro de la codificación alemana que finalmente adoptó la visión liberal decimonónica. Pero no podemos ignorar que las consecuencias al menos en Alemania con el atacamiento y sobrecarga de los tribunales se hicieron sentir prontamente.

Resulta también curioso como algún autor identifica el fenómeno de la publicitación del proceso civil con códigos procesales totalitarios como el de la ex Unión Soviética o el código nazi de 1937. El error histórico es manifiesto si se considera el solo instrumento procesal dentro de un sistema totalitario, de hecho desconoce este aporte que el rol oficioso y pro activo del juez es el actualmente receptado en Europa del Este luego de la caída del comunismo y como reacción a él con fuerte influencia alemana y austríaca. También es curioso como el propio código procesal civil vigente de la Unión Soviética y el actual código procesal chino dan un rol activo al juez ${ }^{91}$. Al parecer los

${ }^{87}$ Cipriani, Franco, Autoritarismo e garantismo nel processo civile, en Rivista di Diritto Processuale, 1 (1994), pp. 24-61; Cipriani, Franco, Il processo civile italiano tra efficienza e garanzie, en Rivista Trimestrale di Diritto Processuale Civile, 4 (2002), pp. 1243-1261.

${ }^{88}$ Monteleone, Girolamo, Principi e ideologie del processo civile: impressioni di un "revisionista", en Rivista Trimestrale di Diritto Processuale Civile, 2 (2003), pp. 575-582.

${ }^{89}$ Alvarado Velloso, El garantismo procesal (s.d., s.l.), passim [disponible en: www.derecho-azul.org/congresoprocesal/Alvarado.htm].

${ }^{90}$ Montero Aroca, Juan, Los principios politicos de la nueva Ley de Enjuiciamiento Civil. Los poderes del juez y la oralidad (Valencia, 2001), pp. 65-72.

${ }^{91}$ Véase en detalle: VAN RHEE, C. H. - Fu, Yulin, The Role of the Judge and Parties in Civil Litigation in Chile and Europe: An Introduction, en VAN Rhee, C. H. - Fu, Yulin, Civil Litigation in China and Europe, Essays on the Role of the Judge and the Parties (New York - London, 2014), pp. 1-37. 
contextos políticos e instrumentos jurídico-procesales orgánicos no condicen con los calificativos de esta corriente autoproclamada "garantista". Estas visiones que tienden a un verdadero revisionismo, al menos en lo que a justicia civil refiere, parte de enfrentar binomios ya superados: pretender por hoy por hoy considerar antónimos la celeridad, economía, eficiencia y eficacia procesal frente al debido y justo proceso como si no formaran parte de él parece no ser acertado. Es más, resultaría altamente cuestionable entonces de qué forma se fueron recolectando y replicándose en el proceso civil comparado europeo los modelos de un juez activo en normas procesales tales como las del Reino Unido ${ }^{92}$ y el código procesal civil vigente alemán, las propuestas del proyecto de principios transnacionales de proceso civil. Quizás el error siempre manifiesto del revisionismo -como otrora lo hizo la práctica y aplicación del Código Josefina de 1781- esté en confundir el proceso con los intereses y el objeto que en él se discuten. En otras palabras la visión de la propia utilización, entendiendo ello como que el proceso pertenece y es de propiedad de las partes porque son éstas en sus intereses privados las que lo ponen en movimiento. Este grave error atenta contra las garantías fundamentales del justo y debido proceso, aquellas garantías que dicen estas visiones defender ${ }^{93}$.

Los intereses en juego, el objeto y aquello que se discute en el proceso son esencialmente de las partes y ello no podría ser desconocido. Otra cosa es el instrumento en el cual las partes deciden emplear para dejar traslucir su controversia para que sea resuelta dentro justamente de un ámbito y una función pública ${ }^{94}$.

2. "Procedural fairness" y la reconciliación de la eficiencia, eficacia, celeridad, economia y derechos fundamentales procesales.

Cuando se analiza una cuestión de justicia procesal a partir de la óptica de una teoría de los derechos y se encuentra un obstáculo visto como un cálculo utilitarista que finalmente coloca en un segundo plano la propia existencia de ese tipo de justicia (la procedimental) es necesario hacer ciertas precisiones. Se debe pues precisar el significado de lo que es el tratamiento equitativo y justo. Según lo sostiene Dennis Galligan el tratamiento equitativo tiene diferentes sentidos según los contextos más aún en el que es relevante al proceso. La idea base es que cada persona debe ser tratada de acuerdo a los

${ }_{92}$ Véase igualmente: WANG, Fuhua, From "Trial Management" to Case Management”, en Van Rhee, C. H. - Fu, Yulin, Civil Litigation, cit. (n. 91), pp. 59-68.

${ }^{93}$ Koller, Christian, The Franz Klein Heritage and Beyong, en Uzelac (coordinador), Goals of Civil, cit. (n. 85), pp. 35 ss.

${ }^{94}$ Uzelac, Alan, Global Developments-Towards Harmonisation (and Back), en UzelaC (coordinador), Goals of Civil, cit. (n. 85), p. 3 ss. 
patrones que gobiernan la vida en sociedad. Patrones que se manifiestan en la autoridad, y esta por esencia es la legal, es decir, toda persona sea tratada en forma ecuánime de acuerdo a dichos patrones ("fairness") 95 . De este pasaje podría inferirse que las reglas procesales son sin duda una parte importante de la noción de justicia procedimental es por eso que puede llegar a afirmarse que la justicia procedimental impone que una persona sea tratada con justicia y equidad conforme al contenido de las normas procesales.

Eso puede también significar que la justicia procesal depende en cierta medida de la conformación que sea dada por el legislador al ejercicio de los derechos procesales. La dificultad aquí se manifiesta pues en saber determinar a partir de cuáles criterios puede el legislador conformar el procedimiento o restringir las áreas de libertad de las partes en el uso de sus derechos procesales. Una primera consideración es tener en cuenta que es difícil para cualquier teoría no utilitarista fijar límites a estos derechos, en otras palabras toda implementación de derecho cuesta, genera gastos, aun cuando sean compensables con los beneficios. Es por ello que los derechos procesales no podrían estar totalmente inmunes a cálculos de eficiencia, ya que estos derechos son ejercidos dentro de un marco orgánico-procedimental de una función pública y por ende existe un todo inherente a su ejercicio que no puede ser desconsiderado ${ }^{96}$. Es así que justamente razones de carácter económicas, la ponderación de tiempo y dinero, además de la necesidad de ponderaciones deontológicas necesarias de justicia imponen evaluar el costo de la limitación de un derecho procesal a favor de otro. Es acá donde entra en juego la importancia del principio o de la máxima de economía procesal que no es sino la aplicación del principio a los derechos procesales y sus limitaciones cuyo destinatario es el legislador ${ }^{97}$. Ello para distinguirlo de la economía procesal en sentido estricto o aquella cuyo destinatario es la institución u órgano destinado a aplicar las normas procedimentales a un caso. En el caso del proceso judicial el órgano jurisdiccional puede acudir a estos principios o máximas procesales tanto como norma interpretativa como así también en calidad de estándares para admitir o denegar determinada alternativa procedimental. Nadie discute el rol de la eficacia y del eficiencia por ejemplo dentro del actuar de la administración pública en el cauce del procedimiento administrativo en base a la necesidad de una adecuada distribución de los escasos recursos del Estado. En nuestro caso también es aplicable ese pos-

${ }^{95}$ Galligan, Denis, Due Process and Fair Procedures (Oxford, 1996), p. xvi.

${ }^{96} \mathrm{KocH}$, Raphael, Mitwirkungsverantwortung im Zivilprozess (Tübingen, 2013), pp. 5-10, 330 ss.

${ }^{97}$ Rechberger, Walter, Economy and Efficiency of Civil Procedure Versus Litigation Culture. An Austrian Perspective, en Recent Trends in Economy and Efficiency of Civil Procedure (Vilnius, 2013), pp. 225 ss. 
tulado pero en relación a los recursos de la Justicia y que imponen limitar o ampliar el ejercicio de determinados derechos en el proceso.

Forma parte intrínseca la garantía de una limitación o reconocimiento de un derecho en forma equitativa. El pensamiento en eficiencia del proceso civil contempla la adecuada gestión de los recursos en un proceso considerado y considerando al mismo en el contexto de todos los otros procesos existentes y de aquellos que podrían ocupar su lugar, lo que justamente ya había sido planteado de alguna forma por Franz Klein ${ }^{98}$. Además la dirección justa y eficiente del proceso implica una economía en el ingreso de causas, en el costo y tiempo de duración de las causas ingresadas como así también en el costo y tiempo de duración para la obtención de una sentencia lo más legitimada y ajustada a lo justo. Ello implica poder oír versiones diferentes, y hasta contradictorias entre sí en ejercicio de sus derechos procesales a las partes para sustentar una posición sustantiva victoriosa. La dirección procesal atribuida en responsabilidad al tribunal no excluye reconocer responsabilidad y roles a las partes dentro del proceso, sino más bien una correcta distribución de costos, tiempo y recursos bajo la dirección de quien ejerce la función jurisdiccional ${ }^{99}$. Control que a su vez es regido por el principio de razonabilidad que no sólo obliga al juez en relación al ejercicio de derechos procesales por las partes en un proceso en concreto para impedir el uso ineficiente y arbitrario de la herramienta procesal. También permite que las partes controlen al órgano jurisdiccional el ejercicio de sus facultades y potestades ${ }^{100}$.

\section{CONCLUSIONES}

Las propuestas tanto de Klein como las observaciones que hiciera Wach no son sino transparentar y objetivar una adecuada gestión del proceso donde no se anulan ni se excluyen responsabilidades ni roles. Ello es las partes siguen asumiendo y detentando los poderes de siempre en relación al objeto litigioso e incluso en algunos aspectos al proceso mismo. El rol activo del tribunal los magnifica y adecua en lugar de limitarlos. Más bien puede decirse que se explicitan las responsabilidades de cada uno frente y dentro de un proceso sincerando las finalidades de éste y los recursos con los que se cuenta para la consecución de ello en cada caso concreto.

Existe como límite el trato equitativo a las partes permitiendo o limitan-

\footnotetext{
${ }^{98}$ ReChberger, Walter, Economy, cit. (n. 97), pp. 225 ss.

${ }^{99}$ Cadiet, Loïc - Normand, Jacques - Amrani Mekri, Soraya, Théorie générale du process (Paris, 2010), pp. 201-204.

${ }^{100}$ Véase el excelente estudio de PICó I JUNOY, Joan, Il diritto processuale tra garantismo ed efficacia: un dibattito mal impostato, en Studi di Diritto Processuale Civile in onore Giuseppe Tarzia (Milano, 2005), I, pp. 213 ss.
} 
do el ejercicio de sus derechos procesales no porque el proceso sea o no de propiedad de las partes o los intereses y el objeto pierdan su carácter privado, sino porque las partes decidieron libremente someter su conflicto particular a una de las funciones del Estado, sujeta al principio de proporcionalidad en sentido lato o razonabilidad.

\section{BIBLIOGRAFÍA}

Abolonin, Vadim - Abolonin, Gleb, Truth and Efficiency in Russian Civil Procedure, en Van Rhee, C. H.- Uzelac, A. (coordinadores), Truth and Efficiency in Civil Litigation (Cambridge, Intersentia, 2012).

Alvarado Velloso, El garantismo procesal (s.d., s.l.), passim [disponible en: www. derecho-azul.org/congresoprocesal/Alvarado.htm].

ANDrews, Neil, On Civil Procedure, Court proceedings (Cambridge, 2013).

BÄHr, Die neuen osterreichischen Civilprozess-Gesetzentwurfe, en Zeitschrift für Zivilprozessrecht, 19 (1894),

BeCKer-Eberhard, Ekkehard, Grundlagen und Grenzen des Verhandlungsgrundsatzes, en YildiRIm, Kamil (coordinador), Zivilprozessrecht im Lichte der Maximen (Estambul, 2001), 15.

Bentham, Jeremy, Rationale of Judicial Evidence Specially Applied to English Practice (London,1827), I.

Bӧнм, Peter, Parteiautonomie versus Richtermacht; die Verantwortung für die Programierungdes Verfahrensablaufes, en Bajons, Ena Marlis - BöHm, Peter - Marinelli, Marino (coordinadores), L'attualità della reforma processuale e sociale di Franz Klein/ Die aktualität der Prozess- und Sozialreform Franz Kleins (Trento, 2011).

Böнm, Peter, Zu den rechtstheoretischen Grundlagen der Rechtpolitik Franz Kleins, in HoFmeister, Herbert (coordinador), Forschungsband Franz Klein(1854-1926). Leben und Wirken (Wien, 1988).

Bolard, G., voz “Motulsky (Henri)", en Cadiet, L. (coordinador), Dictionnaire de la Justice (Paris, 2004).

BRÄNDli, Beat, Prozessökonomie im schweizerischen Recht (Bern, 2013).

Cadiet, Loïc - Normand, Jacques - Amrani Mekni, Soraya, Théorie générale du process, (Paris, 2010).

CADIET, Loïc, Introduction to French Civil Justice System and Civil Procedural Law, en Ritsumeikan University Law Review (2011).

CAdiet, Loï, The International Sources of French Civil Procedure, en Deguchi, M. - Storme, M. (editores), The Reception and Transmission of Civil Procedural Law In The Global Society (Antwerpen - Apeldoorn, Maklu, 2008).

Cadiet, Loï-Jeuland, Emmanuel, Droit judiciaire privé (Paris, 2013).

Cipriani, Franco, Autoritarismo e garantismo nel processo civile, en Rivista di Diritto Processuale, 1 (1994).

Cipriani, Franco, Il processo civile italiano tra efficienza e garanzie, en Rivista Trimestrale di Diritto Processuale Civile, 4 (2002).

Cornu, G. - Foyer, J., Commentaire de la Réforme judiciaire (22 décembre 1958) (Paris, 1960).

Cornu, G., L'avènement du nouveau Code de procédure civile. La codification, en Cour 
DE CASSATION (coordinador), Le nouveau Code de procédure civile: vingt ans après (Paris, 1998).

Cornu, G., L'élaboration du Code de procédure civile, en Revue d' histoire des facultés de droit et de la science juridique (1995).

Damrau, Jürgen, Der Einfluss der Ideen Franz Kleins auf den Deutschen Zivilprozess, en Hofmeister, H. (coordinador), Forschungsband Franz Klein(1854-1926). Leben und Wirken (Wien, 1988).

De Boor, Hans Otto, Die Auflockerung des Zivilprozesses (Tübingen, 1939).

DE Boor, Hans Otto, Rechtstreit einschliesslich Zwangsvollstreckung (Berlin, 1940).

Demelius, Ernst, Kritische Studien zu den Gesetzentwürfen aus dem Jahre 1893 (Wien, 1895), II.

Fasching, Hanns W., Die Weiterentwicklung des österreichischen Zivilprozessrechts im Lichte der Ideen Franz Kleins, en HoFMEISTER, Herbert (coordinador), Forschungsband Franz Klein (1854-1926). Leben und Wirken (Wien, 1988).

Frodu, Susanne, The Heritage of the Franz Klein Reform of Austrian Civil Procedure in 1895-1896, en Civil Justice Quaterly, 31 (2012) 1.

Galligan, Denis, Due Process and Fair Procedures (Oxford, 1996).

GotTwald, Peter, Die osterreichische Zivilprozessordnung aus deutscher Sicht, en Mayr, P. G. (coordinador), 100 Österreichische Zivilprozessgesetze (Wien, 1998).

Hofmeister, Herbert, Franz Klein als Sozialpolitiker, insbesondere auf dem Gebiete des Privatrechts, Forschungsband Franz Klein (Wien, 1988).

Jeuland, Emmanuel, Case Management in France, en Van Rhee, C. H. - Fu, Yulin (coordinadores), Civil Litigation in China and Europe, Essays on the Role of the Judge and the Parties (New York, London, 2014).

JEUland, Emmanuel, La conception du procés civil dansle Code deprocédure civile de 1975, en Cadiet, L. - Canivet, G. (editores), 1806-1976-2006, de la commémoration d'un code à l autre: 200 ans de procédure civile en France (Paris, 2006).

$\mathrm{KISCH}$, Guido, Adolf Wach und die österreichise Rechtswissenschaft (s.1., 1926).

KLEIN, Franz - ENGEL, Friedrich, Der Zivilprozess Österreichs (Mannheim, 1927).

KLEIN, Franz, "Pro Futuro". Betrachtungen über Probleme der Civilprozeßreform in Österreich (Wien, 1891).

KLEIN, Franz, Civilprozess-Gesetzentwürfe, en Zeitscherift für Zivilprozessrecht, 19 (1893).

KLEIN, Franz, Die österreichischen Civilprozess-Gesetzentwürfe, en Zeitschrift für Zivilprozess, 19 (1893).

KLEIN, Franz, Die Schuldhafte Parteihandlung. Eine Untersucubung aus dem Civilprozessrechte (Wien, 1885).

KLEIN, Franz, Gewahrte Freihaeit bei gewährter Hilfe (reimpresión Freiburg [Breisgau] 1973).

KLeIn, Franz, Zeit- und Geistesströmungen im Prozesse (Frankfurt a. M, 1943).

KосH, Raphael, Mitwirkungsverantwortung im Zivilprozess (Tübingen, 2013).

Koller, Christian, The Franz Klein Heritage and Beyong, en UzelaC (coordinador), Goals of Civil, cit. (n. 85), pp. 35 ss.

KöNIG, Bernhard, Die österreichische Zivilprozessordnung und das Königreich Italien, en Juristische Blätter (1981).

Kralik, Winfried, Die Verwirklichung der Ideen Franz Kleins in der Zivilprozeßordnung von 1895, en HofmeISTER, Herbert (coordinador), Forschungsband Franz Klein(1854-1926). Leben und Wirken (Wien, 1988). 
LANGER, Adalbert, Männer und die österreichische Zivilprozessordnung (Wien, 1895, reimpresión 1990).

LeONHARD, Otto, Zur Geschichte der österreichischen Justizreform vom Jahre 1898, en GERÖ, J. (coordinador), Festschrift 50 jahre österreichischen Zivilprozessordnung (Wien, 1948).

Magendie, J.-C., Célérité et qualité de la justice. La gestion du temps dans le procès, en La documentation française (Paris, 2004).

Monteleone, Girolamo, Principi e ideologie del processo civile: impressioni di un "revisionista", en Rivista Trimestrale di Diritto Processuale Civile, 2 (2003).

Montero Aroca, Juan, Losprincipios politicos de la nueva Ley de Enjuiciamiento Civil. Los poderes del juez y la oralidad (Valencia, 2001).

Morel, René., Traité élémentaire de procédure civile (2a edición, Paris, 1949).

Motulsky, Henry, Prolégomènes pour un futur Code de procédure civile: la consécration des principes directeurs du procés civil par le décret du 9 septembre 1971 (Paris, Dalloz, 1972), Chronique, XVII, en Motulsky, H., Ecrits, I : Études et notes de procédure civile (Paris, 1973).

Oberhammer, Paul - Domej, Tanja, Germany, Switzerland, Austria (ca. 1800-2005), en van Rhee, C.H. (coordinador), European Traditions in Civil Procedure (Antwerpen - Oxford, 2005).

Oberhammer, Paul, Richtermacht, Warheitsplicht und Parteienvertretung, en KRALIK - Rechberger (coordinadores), Konfliktvermeidung und Konflicktregelung (Wien, 1983).

Parodi, C., L'esprit général et les innovations du Nouveau Code de procédure civile, en Defrénois (1976).

Picó I JUNOY, Joan, Il diritto processuale tra garantismo ed efficacia: un dibattito mal impostato, en Studi di Diritto Processuale Civile in onore Giuseppe Tarzia (Milano, 2005), I.

ReChBERGER, Walter, Die Ideen Franz Kleins und ibre Bedeutung für die Entwicklung des Zivilprozessrechts in Europa, en Ritsumeikan University Law Review (2008).

Rechberger, Walter, Economy and Efficiency of Civil Procedure Versus Litigation Culture. An Austrian Perspective, en Recent Trends in Economy and Efficiency of Civil Procedure (Vilnius, 2013).

Rounette, G., L'influence en France de la science allemande du procès civil et du Code de procédure civile allemand, en HaBSCHEID, W.J., Das deutsche Zivilprozessrecht und seine Ausstrablung auf andere Rechtsordnungen, (Bielefeld, 1991).

Schilbach, Luisa-Carlota, Die Wesentlichen Grundzüge der Geschichtlichen Entwicklung des ordentlichen prozesses, (Heidelberg, 1937).

Schмidt, AdolfWach, en Zeitschrift für Zivilprozessrecht, 100 (1987).

SELlERT, Wolfgang, Die Reichjustitzgesetze von 1877, Ein gedenkwürdiges Ereignis? en Juristische Schulung (1977).

SPERL, Hans, Franz Klein t, en Zeitschrift für Zivilprozessrecht, 51 (1926).

SPRUNG, Rainer, Der Lebensweg Franz Klein, en Hofmeister, Herbert (coordinador), Forschungsband Franz Klein (1854-1926). Leben und Wirken (Wien, 1988).

SPRUnG, Rainer, Die Ausgangspositionen österreichischer Zivilprozessualistik und ihr Einluss auf das deutsche Recht, en Zeitschrift für Zivilprozess, 92 (1979).

SpRUnG, Rainer, Die Grundlagen des österreichischen Zivilprozessrechts, en Zeitschrift für Zivilprozessrecht, 90 (1977). 
SPRUNG, Rainer, Franz Klein (24.4.1854-6.4.1926) Eine analysierende Lebensskizze, en Franz Klein Symposium (Wien, 2005).

Unger, Dagmar, Adolf Wach (1843-1926) und das liberale Zivilprozessrecht (Berlin, 2005).

Uzelac, Alan, Global Developments-Towards Harmonisation (and Back), en UzelaC (coordinador), Goals of Civil Justice and Civil Procedure in the Contemporary World, (New York - London, 2014).

VAN RheE, C. H. - Fu, Yulin, The Role of the Judge and Parties in Civil Litigation in Chile and Europe: An Introduction, en Van Rhee, C. H. - Fu, Yulin, Civil Litigation in China and Europe, Essays on the Role of the Judge and the Parties (New York - London, 2014).

Van Rhee, C.H. - Uzelac, Alan, The Pursuit of Truth in Contemporary Civil Procedure: Revival of Accuracy or New Balance in Favor of Effectiveness? en VAN RHEE, C. H.UzelaC, A. (coordinadores), Truth and Efficiency in Civil Litigation (Cambridge, Intersentia, 2012).

Van Rhee, C.H., Civil Justice in Pursuit of Efficiency, en Uzelac (coordinador), Goals of Civil Justice and Civil Procedure in the Contemporary World (New York - London, 2014).

VERKERK, Remme, What is Judicial Case Management? en VAN RheE, Remco (coordinador), Judicial Case Management and Efficiency in Civil Litigation (Antwerpen - Oxford, 2008).

WACH, Adolf, Verhandlungen des 26 DJT (Berlin, 1902), II.

W ACH, Adolf, Der Rechtsschutzanspruch, en Zeitscherift für Zivilprozessrecht, 32 (1904).

WACH, Adolf, Die Mündlichkeit in dem Entwurf der Österreichischen Zivilprozessordnung (Wien, 1895).

WaCH, Adolf, Die Novelle zur Civilprozessordnung, en Deutsche Juristen Zeitung, 4 (1898).

WACH, Adolf, Grundfragen und Reform des Zivilprozesses (Berlin, 1914).

WACH, Adolf, Vorträge über die Reichs-Civilprocessordnung, gehalten vor praktischen Juristen im Frühjahr (Bonn, 1879).

WaCH, Adolf, Wie Ich Jurist wurde? en Deutsche Juristenzeitung, 14 (1919).

Wang, Fuhua, From Trial Management to Case Management, en VAN RHEe, C. H. Fu, Yulin, Civil Litigation in China and Europe, Essays on the Role of the Judge and the Parties (New York - London, 2014).

Wijffels, Alain, French Civil Procedure (1806-1975), en van RheE, C.H. (coordinador), European Traditions in Civil Procedure (Antwerpen - Oxford, 2005).

ZeIller, F. von, Grundsätze über die Haupteigenschaften einer Civil-Gerichtsordnung, en Jährlicher Beytrag zur Gesetzkunde und Rechtswissenschaft, 3 (1808). 
